\title{
Diabetes and cardiovascular disease: from new mechanisms to new therapies
}

\author{
Grzegorz Gajos \\ Department of Coronary Disease and Heart Failure, Institute of Cardiology, Faculty of Medicine, Jagiellonian University Medical College, Kraków, Poland
}

\section{KEY WORDS}

cardiovascular complications, diabetes, GLP-1 receptor agonists, hypoglycemia, SGLT2 inhibitors
Correspondence to: Grzegorz Gajos, MD, PhD, Klinika Choroby Wieńcowej i Niewydolności Serca, Instytut Kardiologii, Wydział Lekarski,

Uniwersytet Jagielloński Collegium Medicum, Krakowski Szpital

Specjalistyczny im. Jana Pawła II, ul. Prądnicka 80, 31-202 Kraków, Poland, phone: +48 797188726 email: grzegorz.gajos@uj.edu.pl Received: March 25, 2018 Revision accepted: March 25, 2018. Published online: March 26, 2018 Conflict of interest: $\mathrm{GG}$ received lecture fees from AstraZeneca, Boehringer Ingelheim, Novo Nordisk, and Servier Polska.

Pol Arch Intern Med. 2018;

128 (3): 178-186 doi:10.20452/pamw.4227 Copyright by Medycyna Praktyczna, Kraków 2018

\begin{abstract}
Diabetes increases the risk of cardiovascular (CV) diseases, which are the leading cause of mortality among diabetic patients. Although hyperglycemia is a major determinant of macrovascular and microvascular complications in diabetes, hypoglycemia and glycemic variability have also a strong influence on the cardiovascular system. This overview presents the current state of knowledge on the impact of type 2 diabetes on the CV system and new therapeutic strategies that have been recently developed to correct glucose metabolism disorders in patients with high CV risk, such as glucagon-like peptide 1 receptor agonists, dipeptidyl peptidase-4 inhibitors, and sodium-glucose cotransporter-2 inhibitors. Results of several large randomized clinical trials (such as EMPA-REG, LEADER, SUSTAIN-6, and CANVAS) assessing the efficacy and safety of drugs based on new mechanisms deserve attention due to their beneficial effect on serious CV events, including CV death, myocardial infarction, and stroke. In addition, based on the results of recent studies and meta-analyses, an attempt was made to answer the questions of whether the actions of new drugs are mediated solely by the glucose-lowering effect and whether indeed glycemic control affects the survival of patients with diabetes and CV risk, which seems of key importance from the clinical perspective.
\end{abstract}

Introduction Diabetes is one of the most common diseases in the world. It is estimated to occur in 382 million people, and the number of patients may increase to 592 million by $2035 .{ }^{1}$ According to the World Health Organization data, in 2012, 1.5 million deaths were related to this disease. ${ }^{2}$ The main cause of morbidity and mortality among diabetic patients is cardiovascular disease (CVD), including atherosclerosis and its clinical consequences (coronary heart disease, myocardial infarction [MI], and stroke). Compared with patients without diabetes patients, diabetic individuals have twice the relative risk of cardiovascular (CV) death. ${ }^{3}$

$\mathrm{CV}$ complications in diabetes are associated with hyperglycemia and other glycemic abnormalities. ${ }^{4}$ Moreover, the increased risk of macrovascular atherosclerosis-based complications in patients with type 2 diabetes (T2DM) is associated with the presence of chronic inflammation, dyslipidemia, hypertension, and accompanying diseases and depends on the duration of diabetes and age of the patient. ${ }^{5}$ Increased cardiometabolic risk is also associated with higher epicardial fat thickness in diabetic patients. ${ }^{6}$ Also, microangiopathic complications in patients with T2DM are associated with carotid plaque score. ${ }^{7}$ Therefore, diabetes therapy, oriented not only at normalizing blood sugar, but also at minimizing the risk of $\mathrm{CV}$ events, must be multifactorial and requires cooperation of a diabetologist, cardiologist, nephrologist, and physicians of other specialties. ${ }^{8}$

This paper presents the current state of knowledge on the impact of glycemic disorders on the $\mathrm{CV}$ system and new mechanisms that have been developed recently to correct glucometabolic disturbances in patients with high CV risk. In addition, based on the results of recent clinical trials and reviews of studies and meta-analyses, an attempt was made to answer the question of whether glycemic control affects the survival of patients with diabetes and CV risk, which seems important from the practitioner's point of view.

Postprandial hyperglycemia The influence of postprandial glycemia on the development of diabetes complications has been consistently neglected for many years. The commonly used glycemic 
parameters, such as fasting glucose and glycosylated hemoglobin $\mathrm{A}_{1 c}\left(\mathrm{HbA}_{1 c}\right)$ levels, do not include short-term but significant increases in glucose levels after meals (hyperglycemia spikes). Moreover, neither fasting glucose nor $\mathrm{HbA}_{1 c}$ was able to fully explain the effect of glycemic abnormalities on CV risk in patients with diabetes. Contrary to what was previously expected, the relationship between macroangiopathy and fasting glycemia or $\mathrm{HbA}_{1 c}$ levels was found to be weaker than that observed in the case of microangiopathic complications. ${ }^{9}$ More attention was therefore paid to the impact of postprandial glucose.

Experimental and clinical studies have also demonstrated short-term and long-term effects of postprandial glycemia on the function of the vascular endothelium in both healthy and diabetic patients. ${ }^{10-12}$ Glycemic spikes occurring after a meal may cause impairment of nitric oxide-dependent endothelial functions, activation of blood coagulation, increase of adhesin production, and enhanced oxidative stress. ${ }^{13}$ The relationship between postprandial hyperglycemia and the intima-media thickness, an early marker of CVD, has been demonstrated. ${ }^{14}$

The relationship between high glucose levels after a meal and the risk of $C V$ events has been documented in epidemiological studies. ${ }^{15-17}$ Results obtained by the DECODE research group,${ }^{15}$ evaluated fasting blood glucose and blood glucose levels 2 hours after oral loading of 75 g glucose (equivalent to postprandial glycemia). It was based on data from 13 European prospective cohort studies including a total of 25364 people, at least 30 years of age, and with an average follow-up of 7.3 years. ${ }^{15}$ The analysis clearly showed that the increase in glycemia in the second hour after loading is a stronger risk factor for $\mathrm{CV}$ death and independent of fasting blood glucose.

Cavalot et $\mathrm{al}^{18}$ observed 505 consecutive patients with T2DM for the follow-up period of 14 years. At baseline, patients were assessed for classic CVD risk factors and 5 glycemic parameters (including blood glucose 2 hours after breakfast and after lunch). A total of 172 CVD events and 147 deaths were reported. It was observed that both postprandial blood glucose (measured 2 hours after lunch) and $\mathrm{HbA}_{1 c}$ levels predicted CVD occurrence and general mortality also when taking into account classic nonglycemic CVD risks. The results of the post-breakfast tests were less representative due to the low-calorie breakfast composition (cup of coffee, sometimes with a small piece of bread) at the time of study initiation.

A recent retrospective observational real-world cohort study on 646 patients with T2DM was conducted to examine the impact of postprandial hyperglycemia independently of mean $\mathrm{HbA}_{1}$ levels. ${ }^{19}$ During the mean follow-up period of approximately 16 years, CVD affected 78 of 618 patients with no CVD history reported at first visit, and 56 of all 646 patients died. The mean values of blood glucose 2 hours post breakfast were found to be significant predictors of the CVD incidence and general mortality, after adjusting for the number of measurements, mean $\mathrm{HbA}_{1 \mathrm{c}}$ levels, age, sex, and other classic CVD risk factors. The study concluded that postprandial hyperglycemia noted at clinic visits was associated with CVD incidence and all-cause overall mortality independently of the mean $\mathrm{HbA}_{1 c}$ level in patients with T2DM.

Additional evidence for the relationship of postprandial glucose with $\mathrm{CV}$ risk was provided by a meta-analysis of 20 prospective studies, including a total of 95783 patients, with a follow-up of 12.4 years, which showed a significant association between $C V$ risk and glycemia 2 hours post-load. ${ }^{20}$ The authors also emphasized that the progressive relationship between glucose concentrations and $\mathrm{CV}$ risk occurs below the level of glycemia determining the diagnosis of diabetes.

In addition to postprandial hyperglycemia, the role of postprandial lipotoxicity is increasingly underlined as an important mechanism in the pathogenesis of CVD. Many studies have shown that postprandial increases in triglyceride levels and postprandial glycemia in an independent and additive manner adversely affect endothelial function and increase inflammation. ${ }^{13,21}$ There is ample evidence to support the hypothesis that hyperglycemia and hypertriglyceridemia are proatherogenic mainly due to intensification of oxidative stress. ${ }^{22}$

In the context of the results of the above studies indicating a significant contribution of postprandial glucose to $\mathrm{CV}$ risk, the question arises as to whether therapeutic interventions specifically targeted at postprandial glucose control have an impact on the reduction of the number of $\mathrm{CV}$ events. Unfortunately, there are no interventional studies with major adverse $C V$ events as the endpoints that would provide evidence that postprandial glucose correction will translate into benefits in terms of lowering CV risk.

In a small study of 23 patients with T2DM and 10 healthy subjects, postprandial hyperglycemia in diabetic patients was shown to influence endothelial function assessed by ultrasound measurement of flow-mediated dilation (FMD) of the brachial artery and that the fast-acting insulin analogue (insulin aspart) improves endothelial function by reducing postprandial hyperglycemia. ${ }^{23}$

A randomized trial that compared the intensive insulin therapy with fast- and long-acting insulin analogues in the multiple daily injection algorithm with standard therapy with human insulin (with intermediate action time-neutral protamine Hagedorn and regular $)^{24}$ showed that in 109 patients with T2DM (61 in the insulin analogue group and 48 in the human insulin group) in whom it was sought to achieve fasting blood glucose of $110 \mathrm{mg} / \mathrm{dl}$ or less and postprandial glycemia of $150 \mathrm{mg} / \mathrm{dl}$ or less, no differences were found in fasting blood glucose levels at 36 months of follow-up. Using the Doppler method, a reduction in the diastolic dysfunction 
was shown in the group where postprandial glycemia was more effectively controlled.

One of the larger studies that focused on postprandial hyperglycemia spike control was the randomized STOP-NIDDM. ${ }^{25}$ A total of 1429 patients with impaired glucose tolerance were enrolled to 2 groups: treated with acarbose (a drug-reducing postprandial hyperglycemia, 714 individuals) and placebo (715 individuals). The effectiveness of acarbose in the prevention of diabetes and reduction in the risk of CVD was assessed. After an average follow-up of 3.3 years, the acarbose group showed a $49 \%$ reduction in the risk of $C V$ events compared with placebo, in addition to a $25 \%$ reduction in the risk of developing T2DM.

Glycemic variability Glycemic variability is another element in the care of diabetic patients, which has recently attracted the attention of diabetologists and cardiologists. Analysis of the results of the frequently cited DCCT (Diabetes Control and Complications Trial) showed that patients treated more intensively had a significantly lower risk of microangiopathic complications compared with patients treated as standard, although the $\mathrm{HbA}_{1 c}$ level in both groups was comparable. ${ }^{26}$ Therefore, it was suggested that there must be another independent factor that determines the risk of developing long-term complications of diabetes on top of glycemic control expressed by $\mathrm{HbA}_{1 c}$. It was suggested that the frequency and amplitude of glycemic variability could be this factor. Numerous studies conducted in vitro and on animal model have shown a causal relationship between the variability in glucose levels over time and abnormalities in endothelial function. ${ }^{27-29}$ These observations have also been confirmed in studies conducted in humans.

One of such studies was conducted by Ceriello et $\mathrm{al},{ }^{30}$ who used the hyperglycemic clamp method in patients with T2DM and healthy subjects. Participants were subjected to constant or variable glucose concentrations within 24 hours, followed by the assessment of endothelial function (by FMD) and oxidative stress marker (plasma levels of nitrotyrosin and urinary levels of 8 -iso-PGF2 $\alpha$ ). The authors showed that glycemic variability over time exacerbates endothelial dysfunction to a greater degree than constantly high glucose levels, and that oxidative stress plays a key role in this phenomenon.

In another recent study, the determinants of autonomic neuropathy of the CV system were evaluated depending on the degree of glycemic control in patients with newly diagnosed T2DM. ${ }^{31}$ It was observed that glycemic variability expressed by the mean amplitude of glycemic excursions (MAGE) index was the only factor showing an independent association with the presence of autonomic neuropathy of the CV system.

Recently, the effect of daily glycemic changes on atherosclerotic plaque morphology was assessed in patients with coronary artery disease using virtual histology intravascular ultrasound. ${ }^{17}$
Glucose variability was expressed as the MAGE index. A significant correlation was found between MAGE and the volume of the necrotic core in the atherosclerotic plaque. Moreover, MAGE was the only independent predictor of the occurrence of thin-cap fibroatheroma-the so called vulnerable plaque characterized by a high risk of rupture. The results of this study might suggest that daily glycemic variability can affect the vulnerability of the atherosclerotic plaque in patients with coronary artery disease during lipid-lowering treatment. Therefore, avoiding glycemic variability may be a therapeutic goal equivalent to the control of dyslipidemia, and contribute to a reduction in the incidence of acute coronary syndromes, the most frequent cause being atherosclerotic plaque rupture.

In another recent study by Constantino et al, ${ }^{32}$ glycemic variability (MAGE and postprandial incremental area under the curve) in patients achieving target $\mathrm{HbA}_{1 c}$ levels $(\leq 7.0 \%)$ was observed to alter the epigenetic regulatory profile on the $\mathrm{p} 66^{\text {Shc }}$ promoter (a key protein of the mitochondrial oxidative stress process). Patients were introduced on an intensive glycemic control for 6 months; however, it did not change adverse epigenetic remodeling (DNA hypomethylation and histone 3 acetylation on the $\mathrm{p} 66^{\text {Shc }}$ promoter) as well as impaired FMD and increased urinary 8-isoPGF ${ }_{2 \alpha}$ levels. Therefore, the study proved that glucose variability might influence the epigenetic mechanisms of sustained chromatic remodeling in patients with T2DM achieving target $\mathrm{HbA}_{1 c}$ levels and lead to $\mathrm{CV}$ complications.

Hypoglycemia Numerous epidemiological studies have shown a relationship between hypoglycemia and an increased risk of CV death. ${ }^{33-35}$ The harmful effect of severe symptomatic hypoglycemia, which may lead to myocardial ischemia, ${ }^{36}$ life-threatening cardiac arrhythmia, and sudden cardiac death, ${ }^{37}$ is particularly well documented. Recent studies have suggested that asymptomatic hypoglycemia and even low blood glucose levels, not yet meeting the criterion of hypoglycemia, may also have a negative impact on the $\mathrm{CV}$ system by adversely influencing endothelial function, weakening of endothelium-dependent vasodilation, enhancement of oxidative stress and inflammation, and promotion of the prothrombotic state as well as a direct impact on the myocardium by increasing the catecholamine outburst, enhancing adrenergic stimulation, and reducing the coronary reserve. ${ }^{38,39}$ In clinical practice, increasing attention is being paid to patients who do not feel symptoms of hypoglycemia and who show an increase in thrombin generation and platelet activity. ${ }^{40}$

In an observational study, Chow et $\mathrm{al}^{41}$ used continuous glucose monitoring (CGM) and 24-hour Holter monitoring in 25 patients with T2DM treated with insulin, with CVD or $2 \mathrm{CV}$ risk factors. Hypoglycemia has been shown to be a frequent phenomenon in these patients - it was 
observed for $6 \%$ of the total CGM recording time and most frequently at night. Importantly, during the hypoglycemic states, mostly asymptomatic, any changes in the electrocardiogram-bradycardia and atrioventricular blocks - were registered in these patients.

More frequent application of CGM in patients with T2DM attracted attention to the detrimental role of hypoglycemia in patients treated with old-generation antidiabetic drugs. Recently, 30 patients with T2DM treated with sulfonylurea $\left(\mathrm{HbA}_{1 c}, 6.9 \%\right)$ were subjected to 48-hour CGM and electrocardiography with ventricular repolarization (QTc) and QT dynamicity analysis. ${ }^{42}$ Episodes of hypoglycemia were identified in $30 \%$ of patients, mostly at night (67\%) and with asymptomatic course (73\%). QTc prolongation and higher QT dynamicity were detected in $70 \%$ of hypoglycemic patients. In these patients, QT abnormalities persisted despite normalization of glycemia, suggesting that sulfonylurea-related hypoglycemia may contribute to $\mathrm{CV}$ complications.

Large studies have compellingly shown that hypoglycemia is a frequent phenomenon in diabetic patients during hypoglycemic therapy, particularly with the use of insulin. The incidence of hypoglycemia and the relationship between hypoglycemia and $\mathrm{CV}$ risk in diabetic patients were analyzed by Khunti et $\mathrm{al},{ }^{43}$ using the data from the English Clinical Practice Research Datalink registry. The analysis included 265867 patients with type 1 diabetes (T1DM; $\mathrm{n}=3260)$ or T2DM ( $\mathrm{n}=10422)$ diabetes, aged 30 years or older, and treated with insulin. Episodes of hypoglycemia were observed in $17.6 \%$ and $14 \%$ of patients with T1DM and T2DM, respectively. Among patients with no history of CVD, hypoglycemic episodes were associated with the increased risk of CV events: by $92 \%$ and $50 \%$ in patients with T1DM and T2DM, respectively. Even higher (2.5-fold) CV risk was observed in patients with T2DM and CVD. What is more, it has been shown that the risk of $\mathrm{CV}$ events persists for a long time. The median time from the onset of the first hypoglycemic episode to the first CV event was 1.5 years in both groups of patients.

A random-effects meta-analysis of hypoglycemia and CVD risk was performed in 10 studies: ADVANCE, VADT, ORIGIN, and others. ${ }^{44}$ The incidence of hypoglycemia ranged from $2 \%$ to $14 \%$, depending on the study. The authors found that severe hypoglycemia was associated with an approximately 2-fold increased risk of CVD in patients with T2DM.

Another observational study, conducted by Elwen et $\mathrm{al},{ }^{45}$ focused on the long-term follow-up of patients who had an episode of severe hypoglycemia and required immediate medical attention. In total, 1835 episodes of hypoglycemia in 1156 patients were analyzed (the share of patients with T1DM and T2DM was comparable: $45 \%$ and $44 \%$, respectively). The annual mortality rate after a hypoglycemic episode was $4.45 \%$ in patients with T1DM and as high as $22.1 \%$ in patients with T2DM.
A 15-year follow-up of 195 patients with at least one severe hypoglycemic episode revealed an increase in the risk of coronary heart disease by $10.8 \%$ and mortality by $28.3 \%$ as early as 3 years after the episode. ${ }^{46}$ The prospective study included 1209 patients with diagnosed diabetes from the Artherosclerosis Risk in Communities monitored in the years 1996-2003. The hypoglycemic episode was not associated with heart failure, atrial fibrillation, or stroke. However, severe hypoglycemia increased the incidence of coronary heart disease by about 2 times, all-cause mortality by about 1.7 times, and cancer mortality by about 2.5 times.

Recently, another analysis of data from the DCCT study was published, enriched with the results of coronary artery calcification assessments by computed tomography. ${ }^{47}$ The effect of hypoglycemia on coronary artery calcification in patient cohorts depending on the degree of glycemic control $\left(\mathrm{HbA}_{1 c}<7.5 \%\right.$ vs $\left.\mathrm{HbA}_{1 c} \geq 7.5 \%\right)$ was assessed. In the group of patients with good glycemic control $\left(\mathrm{HbA}_{1 c}<7.5 \%\right)$, regression of atherosclerotic lesions was observed, whereas progression of such lesions was observed in the group with uncontrolled glycemia. Moreover, there was a positive relationship between the incidence of hypoglycemic episodes and the degree of coronary artery calcification, particularly visible in the group with good glycemic control. The episodes of hypoglycemia in a group with good glycemic control had a greater impact on the progression of atherosclerosis than the lack of glycemic control.

The above studies allow to conclude that in order to achieve the therapeutic goals (glycemic control), the risk of hypoglycemia should be considered and the treatment should be individualized. This task is particularly difficult in patients requiring insulin treatment, with T2DM, often with a high CV risk, who are most at risk of complications and increased mortality associated with hypoglycemia. Therefore, therapeutic strategies that generate the lowest incidence of hypoglycemia should be used in this group of patients. The strategies should focus not only on proper insulin regimens and technical innovations, but also on patient education and empowerment. ${ }^{37}$

Long-acting insulin analogues have been shown to reduce the risk of hypoglycemia in patients with diabetes. One of the newest analogs is degludec, an ultra-long-acting basal insulin, recently assessed in the DEVOTE study on CV safety. A total of 7637 patients with T2DM and high risk of $\mathrm{CV}$ events received either degludec or glargine (another long-acting insulin analog) once daily in addition to standard care. ${ }^{48}$ It was shown that degludec decreased the rate of severe hypoglycemic episodes by $40 \%$ and nocturnal severe hypoglycemic episodes by $53 \%$ compared with glargine, with a trend towards better CV effectiveness profile. The authors suggested that the improved pharmacodynamic profile of degludec might provide better and safer glycemic control. 


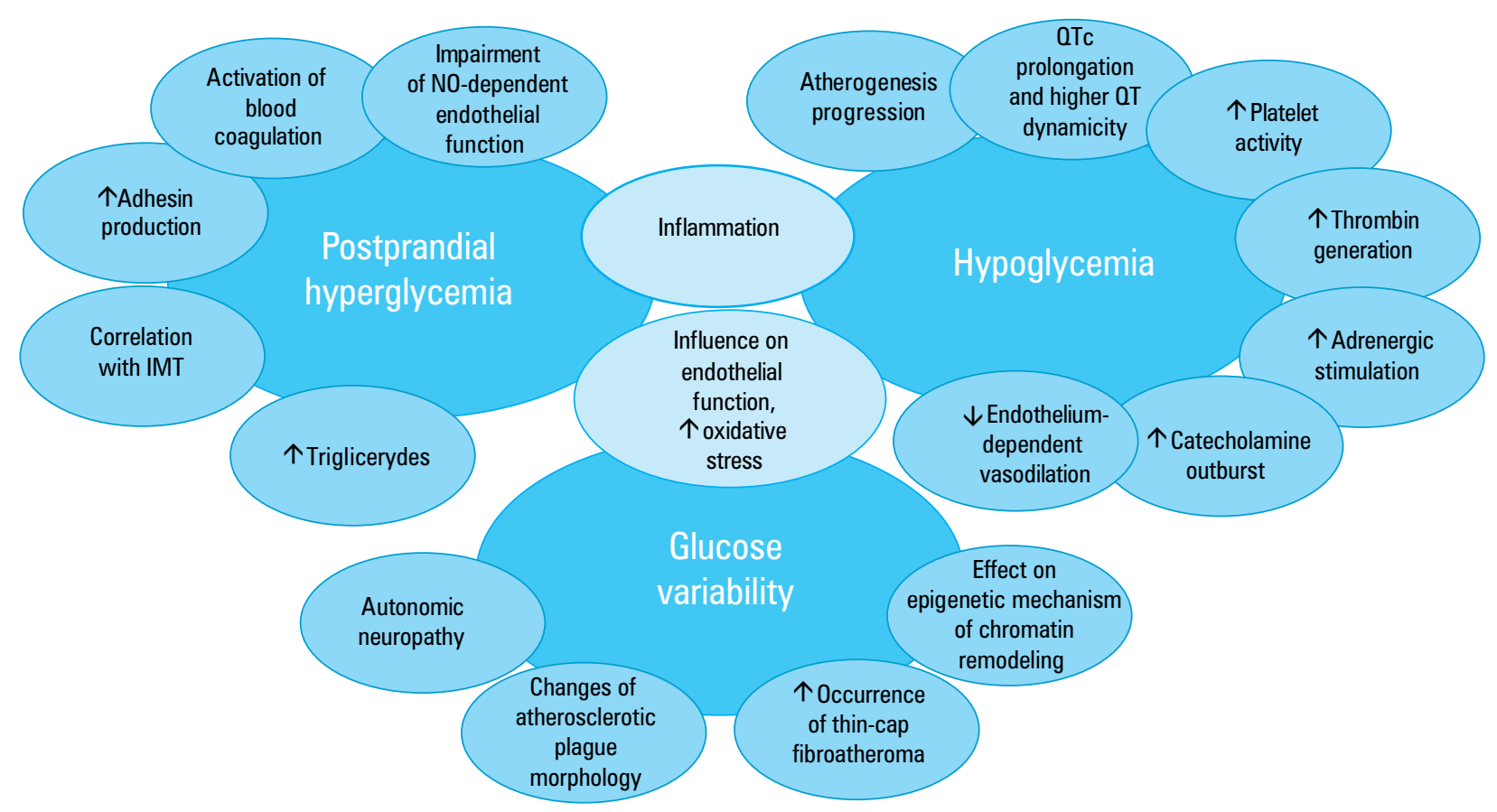

FIGURE 1 Effects of glycemic disturbances on cardiovascular risk in patients with type 1 and type 2 diabetes

Abbreviations: IMT, intima-media thickness; NO, nitric oxide

A summary of the mechanisms underlying the effects of glycemic disturbances on the CV system is presented in FIGURE 1.

Does glycemic control prolong life? Recently, the results of a meta-analysis assessing the effect of intensive glycemic control (alone or as a component of multifactorial treatment) on the risk of nonfatal MI, nonfatal stroke, CV death, and death from any cause in patients with T2DM, were published. ${ }^{49}$ The analysis of 19 randomized clinical trials, including over 84000 patients, showed that intensive glycemic control (as part of multifactorial therapy) is associated with a reduction in the risk of MI, but no reduction (or increase) in incidence of stroke, CV deaths, or total mortality, as compared with standard therapy.

The lack of a clear effect of intensive glycemic control on the prognosis of patients with diabetes raised doubts as to whether the relationship between glycemia and CV risk, often demonstrated in large prospective observational studies, has a causal nature. One of the studies proving the existence of such a relationship is the analysis recently made by Ross et $a l,{ }^{50}$ who used Mendelian randomization, using polymorphic variants of genes previously associated with dysglycemia and diabetes, to assess the consequences of exposure to lifelong glycemic disorders, regardless of other factors and without distortion by inverse relationships. The results of this analysis clearly showed that abnormal fasting glucose insignificantly determined the risk of coronary heart disease, while the increased $\mathrm{HbA}_{1 c}$ values and the presence of diabetes are independent factors increasing this risk. The results of this analysis gave hope that, in the long-term perspective, a treatment strategy based on intensive glycemic control with new-generation antidiabetic drugs should benefit patients with T2DM.

New mechanisms of action and effectiveness of antidiabetic drugs Currently, the 2 most promising directions of clinical intervention are modulation of the incretin system and inhibition of sodium-glucose cotransporter 2 (SGLT2). In the context of improvement of prognosis in patients with T2DM with high CV risk, much interest has been stirred by the positive results of several recent studies assessing the safety and efficacy of drugs based on these mechanisms (liraglutide, semaglutide and empagliflozin, and canagliflozin), with a hard endpoint involving serious $\mathrm{CV}$ events, so called 3-point MACE: composite of CV death, nonfatal MI, and nonfatal stroke. ${ }^{51-54}$ A summary of CV outcomes observed for various antidiabetic drugs is presented in TABLE 1 .

The main therapeutic targets of the incretin system are the intestinal glucagon-like peptide 1 (GLP-1) and the enzyme dipeptidyl peptidase 4 (DPP-4) that rapidly inactivates GLP-1. Incretin hormones play an important role in metabolism, including stimulation of insulin release, suppression of glucagon secretion, delayed gastric emptying after food intake, and satiety. For the treatment of T2DM, 2 classes of medications that enhance incretin action are used: GLP-1 receptor agonists (administered subcutaneously) and DPP-4 inhibitors (oral drugs). Both GLP-1 receptor agonists and DPP-4 inhibitors have been investigated in CV studies in patients with T2DM. The potential role of GLP- 1 in modifying CV risk through a potent glucose-lowering effect accompanied with direct and indirect actions in specific 
TABLE 1 Cardiovascular effects of antidiabetic agents reported in medical experiments and clinical trials

\begin{tabular}{|c|c|c|c|c|c|c|c|}
\hline $\begin{array}{l}\text { Trial name / } \\
\text { Authors }\end{array}$ & Therapeutic target & Tested drug & $\begin{array}{l}\text { Type of } \\
\text { diabetes }\end{array}$ & $\begin{array}{l}\text { No. of } \\
\text { participants }\end{array}$ & $\begin{array}{l}\text { Follow-up } \\
\text { duration }\end{array}$ & $\begin{array}{l}\text { Primary } \\
\text { endpoint }\end{array}$ & $\begin{array}{l}\text { CV outcomes in } \\
\text { drug-treated } \\
\text { group vs placebo }\end{array}$ \\
\hline Ceriello et $\mathrm{a}^{23}$ & Insulin receptors & $\begin{array}{l}\text { Insulin aspart } \\
\text { (insulin analogue) }\end{array}$ & T2DM & 33 & 6 hours & NA & $\begin{array}{l}\text { Improved } \\
\text { endothelial } \\
\text { function }\end{array}$ \\
\hline $\begin{array}{l}\text { Von Birba et } \\
\text { al }^{24}\end{array}$ & Insulin receptors & $\begin{array}{l}\text { Insulin aspart and } \\
\text { insulin detemir or } \\
\text { regular insulin } \\
\text { and NPH }\end{array}$ & T2DM & 109 & 3 years & $\begin{array}{l}\text { Change of } \\
\text { postprandial } \\
\text { plasma } \\
\text { glucose from } \\
\text { baseline to } \\
\text { the end of } \\
\text { study } \\
\text { at } 36 \text { months }\end{array}$ & $\begin{array}{l}\text { Reduction in } \\
\text { diastolic } \\
\text { dysfunction }\end{array}$ \\
\hline STOP-NIDDM ${ }^{25}$ & $\begin{array}{l}\text { Competitive } \\
\text { inhibitor of } \\
\text { intestinal } \\
\text { a-glucosidases }\end{array}$ & $\begin{array}{l}\text { Acarbose (a drug } \\
\text { reducing } \\
\text { postprandial } \\
\text { hyperglycemia) }\end{array}$ & IGT & 1429 & $\begin{array}{c}3.3 \text { years } \\
\text { (mean) }\end{array}$ & $\begin{array}{l}\text { Development } \\
\text { of diabetes }\end{array}$ & $\begin{array}{l}\text { Reduction in: } \\
\text { - risk of CV } \\
\text { events by } 49 \% \\
\text { - incidence of } \\
\text { new cases of } \\
\text { hypertension by } \\
34 \%\end{array}$ \\
\hline \multirow[t]{2}{*}{ DEVOTE ${ }^{48}$} & \multirow[t]{2}{*}{ Insulin receptors } & \multirow[t]{2}{*}{$\begin{array}{l}\text { Degludec (ultra- } \\
\text {-long-acting basal } \\
\text { insulin) }\end{array}$} & \multirow[t]{2}{*}{ T2DM } & \multirow[t]{2}{*}{7637} & \multirow[t]{2}{*}{$\begin{array}{l}2 \text { years } \\
\text { (median) }\end{array}$} & \multirow[t]{2}{*}{ 3-point MACE } & $\begin{array}{l}\text { No significant } \\
\text { reduction in } \\
\text { the risk of MACE } \\
\text { (HR, } 0.91 ; 95 \% \mathrm{Cl} \text {, } \\
0.78-1.06)\end{array}$ \\
\hline & & & & & & & $\begin{array}{l}\text { Reduction in severe } \\
\text { hypoglycemia } \\
\text { episodes by } 40 \%\end{array}$ \\
\hline LEADER $^{51}$ & GLP-1 receptor & $\begin{array}{l}\text { Liraglutide (GLP- } \\
-1 \text { receptor } \\
\text { agonist) }\end{array}$ & T2DM & 9340 & $\begin{array}{l}3.8 \text { years } \\
\text { (median) }\end{array}$ & 3-point MACE & $\begin{array}{l}\text { Reduction in: } \\
\text { - risk of MACE by } \\
13 \% \\
\text { - risk of CV death } \\
\text { by } 22 \%\end{array}$ \\
\hline SUSTAIN-6 ${ }^{52}$ & GLP-1 receptor & $\begin{array}{l}\text { Semaglutide (GLP- } \\
\text {-1 receptor } \\
\text { agonist) }\end{array}$ & T2DM & 3297 & $\begin{array}{c}2.1 \text { years } \\
\text { (mean) }\end{array}$ & 3-point MACE & $\begin{array}{l}\text { Reduction in: } \\
\text { - risk of MACE by } \\
26 \% \\
\text { - rate of nonfatal } \\
\text { stroke by } 39 \%\end{array}$ \\
\hline \multirow[t]{2}{*}{$\begin{array}{l}\text { SAVOR-TIMI 53; } \\
\text { EXAMINE; } \\
\text { TECOS }^{56}\end{array}$} & \multirow[t]{2}{*}{ DPP-4 } & \multirow[t]{2}{*}{$\begin{array}{l}\text { Saxagliptin, } \\
\text { alogliptin, } \\
\text { sitagliptin (DPP- } \\
-4 \text { inhibitors) }\end{array}$} & \multirow[t]{2}{*}{ T2DM } & \multirow[t]{2}{*}{$\begin{array}{l}16492 ; \\
5380 ; \\
14735\end{array}$} & \multirow[t]{2}{*}{$\begin{array}{l}\text { At least } \\
24 \text { weeks }\end{array}$} & \multirow[t]{2}{*}{ 3-point MACE } & $\begin{array}{l}\text { Neutral effect on } \\
\text { primary MACE } \\
\text { outcome in } \\
\text { EXAMINE and } \\
\text { TECOS }\end{array}$ \\
\hline & & & & & & & $\begin{array}{l}\text { Higher rate of HF in } \\
\text { SAVOR-TIMI } 53\end{array}$ \\
\hline EMPA-REG ${ }^{53}$ & SGLT2 & $\begin{array}{l}\text { Empagliflozin } \\
\text { (SGLT2 inhibitor) }\end{array}$ & T2DM & 7020 & $\begin{array}{l}3.1 \text { years } \\
\text { (median) }\end{array}$ & 3-point MACE & $\begin{array}{l}\text { Reduction in: } \\
\text { - risk of MACE by } \\
14 \% \\
\text { - risk of CV death } \\
\text { by } 38 \% \\
\text { - risk of } \\
\text { hospitalization for } \\
\text { HF by } 35 \%\end{array}$ \\
\hline CANVAS $^{54,58}$ & SGLT2 & $\begin{array}{l}\text { Canagliflozin } \\
\text { (SGLT2 inhibitor) }\end{array}$ & T2DM & 10142 & $\begin{array}{l}188.2 \\
\text { weeks } \\
\text { (mean) }\end{array}$ & 3-point MACE & $\begin{array}{l}\text { Reduction in: } \\
\text { - risk of MACE by } \\
14 \% \\
\text { - risk of } \\
\text { hospitalization for } \\
\text { HF by } 33 \%\end{array}$ \\
\hline
\end{tabular}

Abbreviations: Cl, confidence interval; DPP-4, dipeptidyl peptidase 4; GLP-1, glucagon-like peptide 1; HF, heart failure; HR, hazard ratio; IGT, impaired glucose tolerance; MACE, a composite of death from cardiovascular causes, nonfatal myocardial infarction, or nonfatal stroke; NA, not applicable; SGLT, sodium-glucose cotransporter 2; T2DM, type 2 diabetes mellitus

tissues and cell types was shown, for example, heart (increased cardioprotection), blood vessels (reduced blood pressure), fat, other tissues (reduced inflammation), and others. ${ }^{55}$ At least $4 \mathrm{CV}$ outcome studies examining the safety of GLP-1 agonists, such as lixisenatide (ELIXA), exenatide (FREEDOM-CVO), liraglutide (LEADER), and semaglutide (SUSTAIN-6) have been performed 
in patients on a variety of approved antidiabetic therapies. The latter 2 trials yielded particularly interesting results, which are described below.

The LEADER trial ${ }^{51}$ evaluated the safety of liraglutide (a GLP-1 receptor agonist) added to standard treatment compared with placebo in a group of 9340 patients with T2DM and high CV risk. In the 3-year follow-up period (median, 3.8 years), a $13 \%$ reduction in the risk of a composite primary endpoint-MACE-was found in the liraglutide group. Compared with placebo, the liraglutide group showed a $22 \%$ reduction in the risk of CV death and a $15 \%$ reduction in the risk of death from any cause. There was a trend towards a lower incidence of MI, stroke, and hospitalization for heart failure in the liraglutide group, although the differences between the groups were not significant. Moreover, a 22\% reduction in the risk of nephropathy and a reduction in body weight (by $2.3 \mathrm{~kg}$ ) was found in the liraglutide group. In addition to the significantly reduced mortality risk, there was a $31 \%$ reduction in the incidence of severe hypoglycemic episodes and a $20 \%$ reduction in the overall incidence of hypoglycemia (severe and confirmed) in the liraglutide group, compared with placebo.

The results of a recently published SUSTAIN-6 study with semaglutide, another GLP-1 agonist, are also promising. Semaglutide is a GLP-1 analogue with an extended half-life of approximately 1 week allowing for once weekly subcutaneous administration. The CV effects of semaglutide were investigated in a multicenter, randomized, double-blind, placebo-controlled, parallel-group trial in 3297 patients with T2DM and high CV risk. ${ }^{52} \mathrm{~A}$ follow-up of 27 months (median, 2.1 years) revealed a significant reduction in the risk of the primary composite MACE outcome (26\%) in semaglutide-treated patients determined mainly by a significant decrease in the rate of nonfatal stroke (39\%) and a nonsignificant decrease in nonfatal MI (26\%), compared with the placebo group. However, no significant reduction in the rate of death from $\mathrm{CV}$ causes was found. Additional clinical effects were observed in patients receiving semaglutide, namely, sustained reduction in glycated hemoglobin levels, systolic blood pressure (SBP), and body weight, which are postulated as contributors o lowering CV risk.

The second target of incretin system is DPP-4, a key determinant of incretin bioactivity. The results of the first 3 large randomized clinical trials on CV safety of DPP-4 inhibitors, namely, saxagliptin (SAVOR-TIMI 53), alogliptin (EXAMINE), and sitagliptin (TECOS), showed a neutral effect on the primary MACE outcome. Moreover, the SAVOR-TIMI 53 study $^{56}$ revealed a significantly higher rate of heart failure requiring admission to the hospital in the DPP-4 inhibitor-treated group versus the placebo group.

Gliflozins are a relatively new class of antihyperglycemic agents-inhibitors of SGLT2. SGLT2 is a sodium-dependent glucose transport protein responsible for the reabsorption of most filtered glucose in the kidney. Inhibition of SGLT2, besides lowering blood glucose levels, leads to several metabolic effects, such as improvements in insulin sensitivity, reduced glucose toxicity, and weight loss, as well as nonglycemic effects, such as blood pressure lowering and nephroprotection. ${ }^{57}$ Numerous phase 2 and 3 clinical trials have been conducted to assess the benefits and risks of SGLT2 inhibitors, including CV effects. The results of 2 trials (EMPA-REG and CANVAS), described below, deserve attention due to their impact on mortality and heart failure hospitalization.

The EMPA-REG study ${ }^{53}$ was a multicenter, long-term, randomized, double-blind, placebo-controlled trial evaluating the safety of empagliflozin added to standard treatment in a group of 7020 patients with T2DM with high CV risk. Empagliflozin is an SGLT2 inhibitor that acts by blocking the reabsorption of glucose in the kidneys, which leads to its elimination in the urine and lowering of its concentration in the blood. In more than 3 years of follow-up, the empagliflozin group had a $14 \%$ reduction in the risk of MACE events compared with placebo. There were no significant differences in the incidence of MI or stroke, but the empagliflozin group showed a $38 \%$ reduction in the risk of CV death, a $35 \%$ reduction in the risk of hospitalization for heart failure, and a $32 \%$ reduction in death risk for any reason. It is noteworthy that the frequency of hypoglycemic episodes was comparable in both groups. In addition, there was a significant body mass reduction (by $1.4 \mathrm{~kg}$ ) in the empagliflozin group.

The same beneficial effect on body weight, as well as on glycated hemoglobin and blood pressure, was observed in patients treated with canagliflozin, an SGLT2 inhibitor, in the CANVAS study. ${ }^{58} \mathrm{~A}$ total of 10142 patients with T2DM and high CV risk were assessed in a multicenter, double-blind, randomized, placebo-controlled trial for a mean duration of 188.2 weeks. The rate of MACE occurrence was significantly lower in the canagliflozin-treated group (by 14\%) compared with placebo, although without mortality benefit. The MACE rate was higher in patients with T2DM with a prior CV event compared with those without a history of CVD (36.9 vs $15.7 / 1000$ patient-years, $P<0.001) .{ }^{54}$ Additionally, hospitalized heart failure was reduced by $33 \%$. Safety data revealed a 2 -fold increase in the risk of amputation in a group receiving canagliflozin versus placebo.

There are also attempts to investigate new therapies as an additional benefit on top of optimal medical care. Cardioprotective effects of omega-3 polyunsaturated fatty acids ( $n-3$ PUFAs) at a dose of $2 \mathrm{~g}$ have been studied in patients with T2DM. ${ }^{59}$ The results showed no improvement in the metabolic status, including lipid control, insulin sensitivity, and adipokine profile, in patients treated with high doses of n-3 PUFAs and receiving optimal medications for T2DM and CVD. 
The authors concluded that the high effectiveness of modern optimal medical therapy may mask or limit the beneficial effects of n-3 PUFAs. Similarly, another study failed to demonstrate the beneficial effect of $2 \mathrm{~g}$ of $\mathrm{n}-3$ PUFAs on endothelial function indices). ${ }^{60}$ This is particularly interesting in light of the fact that patients with T2DM and unstable glycemic control showed unfavorable serum phospholipid n-6/n-3 PUFA ratio) ${ }^{61}$ and numerous studies provided evidence for the cardioprotective effects of $n-3$ PUFA.

Are beneficial mechanisms of the new drugs mediated solely by the glucose-lowering effect? The detailed analysis of the EMPA-REG and LEADER data revealed that the beneficial $C V$ effect was not directly related to their glucose-lowering effect.

In a recent analysis of the results of the EMPA-REG study adjusted for the control of blood pressure, lipids, and $\mathrm{HbA}_{1 \mathrm{c}}$, the authors showed that the beneficial effect was independent of the control of these parameters (including glycemia). ${ }^{62}$ Therefore, all patients with high CV risk benefited from the treatment with empagliflozin regardless of the magnitude of glucose-lowering effect.

The LEADER study presented an analysis of the results according to the degree of $\mathrm{HbA}_{1 c}$ reduction split by effectiveness tertiles. Liraglutide was equally effective in each of the subgroups: both in change $\leq-1.4 \%$ and in change $>0.4 \% .{ }^{63}$

The exact mechanisms of the beneficial CV effects of both new drug groups are not fully understood. In addition to the hypoglycemic effect, other effects may be involved. In the case of GLP-1 receptor agonists, direct antiatherosclerotic action may be associated with the activation of GLP-1 receptors present in the CV system. Studies have shown that their activation is associated with improvement of endothelial function, reduction of inflammation in the vascular wall, increased stability of atherosclerotic plaques, and reduction of platelet aggregation. Moreover, treatment with GLP-1 receptor agonists resembles multifactorial intervention in diabetes with correction of other $\mathrm{CV}$ risk factors significant body mass reduction, and blood pressure lowering. ${ }^{55}$ In the case of SGLT-2 inhibitors, the modulation of cardiomyocyte metabolism is by ketogenic action and the increase in oxidation of glucose instead of fatty acids. The diuretic effect (without the activation of the adrenergic system) may also be of importance, resulting in blood pressure lowering and prevention of heart failure.

In summary, the results of the EMPA-REG, LEADER, SUSTAIN-6, and CANVAS trials are very promising. In these studies, it was demonstrated for the first time that patients with T2DM, at high CV risk, can be treated effectively (reduce and control glycemia, reduce body weight) and safely (with a reduced risk of $\mathrm{CV}$ death and death in general).

It seems that the new generation of antidiabetic drugs have pleiotropic effects, and they accomplish more than simply lowering the glucose level.
ACKNOWLEDGMENTS The publication was supported by a grant from National Science Centre Poland to G.G. 2011/03/B/NZ5/0576. Editorial assistance was provided by Proper Medical Writing, Warsaw, Poland and funded by Novo Nordisk Poland.

OPEN ACCESS This is an Open Access article distributed under the terms of the Creative Commons Attribution-NonCommercial-ShareAlike 4.0 International (CC BY-NC-SA 4.0) License (http://creativecommons.org/licenses/by-nc-sa/4.0/), allowing third parties to copy and redistribute the material in any medium or format and to remix, transform, and build upon the material, provided the original work is properly cited, distributed under the same license, and used for noncommercial purposes only. For commercial use, please contact the journal office at pamw@mp.pl.

\section{REFERENCES}

1 Guariguata L, Whiting DR, Hambleton I, et al. Global estimates of diabetes prevalence for 2013 and projections for 2035. Diabetes Res Clin Pract. 2014; 103: 137-149.

2 WHO, Global Report on Diabetes. 2016. http://apps.who.int/iris/bitstream/10665/204871/1/9789241565257_eng.pdf?ua=1\&ua=1. Accessed March 20, 2018.

3 Emerging Risk Factors Collaboration, Sarwar N, Gao P, et al. Diabetes mellitus, fasting blood glucose concentration, and risk of vascular disease: a collaborative meta-analysis of 102 prospective studies. Lancet. 2010; 375: 2215-2222.

4 Wang CC, Hess CN, Hiatt WR, et al. Clinical Update: Cardiovascular disease in diabetes mellitus: atherosclerotic cardiovascular disease and heart failure in type 2 diabetes - mechanisms, management, and clinical considerations. Circulation. 2016; 133: 2459-2502.

5 Monnier L, Hanefeld M, Schnell 0 , et al. Insulin and atherosclerosis: how are they related? Diabetes Metab. 2013; 39: 111-117.

6 Seker T, Turkoglu C, Harbalıoglu H, et al. Impact of diabetes on association between epicardial fat thickness and extent and complexity of coronary artery disease in patients with non-ST elevation myocardial infarction. Kardiol Pol. 2017; 75: 1177-1184.

7 Bartman W, Nabrdalik K, Kwiendacz H, et al.Association between carotid plaque score and microvascular complications of type 2 diabetes. $\mathrm{Pol}$ Arch Intern Med. 2017; 127: 418-422.

8 Gernstein H, Jaeschke R. Drugs in diabetes in 2016, changes in endocrinology in 2015. Dr. Hertzel Gerstein in an interview with Dr. Roman Jaeschke. Pol Arch Med Wewn. 2016; 126: 907-908.

9 Ceriello A. Postprandial hyperglycemia and diabetes complications: is it time to treat? Diabetes. 2005; 54: 1-7.

10 Marfella R, Verrazzo G, Acampora R, et al. Glutathione reverses sys temic hemodynamic changes induced by acute hyperglycemia in healthy subjects. Am J Physiol. 1995; 268: E1167-E1173.

11 Kawano H, Motoyama T, Hirashima 0, et al. Hyperglycemia rapidly suppresses flow-mediated endothelium-dependent vasodilation of brachial artery. J Am Coll Cardiol. 1999; 34: 146-154. ¿

12 Giugliano D, Marfella R, Coppola L, et al. Vascular effects of acute hyperglycemia in humans are reversed by L-arginine. Evidence for reduced availability of nitric oxide during hyperglycemia. Circulation. 1997; 95: 1783-1790.

13 Ceriello A, Quagliaro L, Piconi L, et al. Effect of postprandial hypertriglyceridemia and hyperglycemia on circulating adhesion molecules and oxidative stress generation and the possible role of simvastatin treatment. Diabetes. 2004; 53: 701-710.

14 Hanefeld M, Koehler C, Schaper F, et al. Postprandial plasma glucose is an independent risk factor for increased carotid intima-media thickness in non-diabetic individuals. Atherosclerosis. 1999; 144: 229-235. $\square$

15 Glucose tolerance and mortality: comparison of WHO and American Diabetes Associationdiagnostic criteria. The DECODE study group. European Diabetes Epidemiology Group. Diabetes Epidemiology: Collaborative analysis of diagnostic criteria in Europe. Lancet. 1999; 354: 617-621.

16 Hanefeld M, Fischer S, Julius $\mathrm{U}$, et al. Risk factors for myocardial infarction and death in newly detected NIDDM: the Diabetes Intervention Study, 11 year follow-up. Diabetologia. 1996; 39: 1577-1583. [

17 Kuroda M, Shinke T, Sakaguchi K, et al. Effect of daily glucose fluctuation on coronary plaque vulnerability in patients pre-treated with lipid-lowering therapy: a prospective observational study. JACC Cardiovasc Interv. 2015; 8: 800-811. 
18 Cavalot F, Pagliarino A, Valle M, et al. Postprandial blood glucose predicts cardiovascular events and all-cause mortality in type 2 diabetes in a 14-year follow-up: lessons from the San Luigi Gonzaga Diabetes Study. Diabetes Care. 2011; 34: 2237-2243.

19 Takao T, Suka M, Yanagisawa H, et al. Impact of postprandial hyperglycemia at clinic visits on the incidence of cardiovascular events and all-cause mortality in patients with type 2 diabetes. J Diabetes Investig. 2017 8: 600-608. ए

20 Coutinho M, Gerstein HC, Wang Y, et al. The relationship between glucose and incident cardiovascular events. A metaregression analysis of published data from 20 studies of 95,783 individuals followed for 12.4 years. Diabetes Care. 1999; 22: 233-240.

21 Ceriello A, Taboga C, Tonutti L, et al. Evidence for an independent and cumulative effect of postprandial hypertriglyceridemia and hyperglycemia on endothelial dysfunction and oxidative stress generation: effects of shortand long-term simvastatin treatment. Circulation. 2002; 106: 1211-1218. 22 Ceriello A, Genovese S. Atherogenicity of postprandial hyperglycemia and lipotoxicity. Rev Endocr Metab Disord. 2016; 17: 111-116.

23 Ceriello A, Cavarape A, Martinelli L, et al. The post-prandial state in Type 2 diabetes and endothelial dysfunction: effects of insulin aspart. Diabet Med. 2004; 21: 171-175. ᄃ

24 von Bibra H, Siegmund T, Kingreen I, et al. Effects of analogue insulin in multiple daily injection therapy of type 2 diabetes on postprandial glucose control and cardiac function compared to human insulin: a randomized controlled long-term study. Cardiovasc Diabetol. 2016; 15:7.

25 Chiasson JL, Josse RG, Gomis R, et al. Acarbose treatment and the risk of cardiovascular disease and hypertension in patients with impaired glucose tolerance: the STOP-NIDDM trial. JAMA. 2003; 290: 486-494. ¿

26 The relationship of glycemic exposure $(\mathrm{HbA} 1 \mathrm{c})$ to the risk of development and progression of retinopathy in the diabetes control and complications trial. Diabetes. 1995; 44: 968-983

27 Quagliaro L, Piconi L, Assaloni R, et al. Intermittent high glucose enhances apoptosis related to oxidative stress in human umbilical vein endothelial cells: the role of protein kinase $\mathrm{C}$ and $\mathrm{NAD}(\mathrm{P}) \mathrm{H}$-oxidase activation. $\mathrm{Di}$ abetes. 2003; 52: 2795-2804. 주

28 Quagliaro L, Piconi L, Assaloni R, et al. Intermittent high glucose enhances ICAM-1, VCAM-1 and E-selectin expression in human umbilical vein endothelial cells in culture: the distinct role of protein kinase $C$ and mitochondrial superoxide production. Atherosclerosis. 2005; 183: 259-267.

29 Azuma K, Kawamori R, Toyofuku Y, et al. Repetitive fluctuations in blood glucose enhance monocyte adhesion to the endothelium of rat thoracic aorta. Arterioscler Thromb Vasc Biol. 2006; 26: 2275-2280.

30 Ceriello A, Esposito K, Piconi L, et al. Oscillating glucose is more deleterious to endothelial function and oxidative stress than mean glucose in normal and type 2 diabetic patients. Diabetes. 2008; 57: 1349-1354.

31 Xu W, Zhu Y, Yang X, et al. Glycemic variability is an important risk factor for cardiovascular autonomic neuropathy in newly diagnosed type 2 diabetic patients. Int J Cardiol. 2016; 215: 263-268. ¿

32 Costantino S, Paneni F, Battista R, et al. Impact of glycemic variability on chromatin remodeling, oxidative stress, and endothelial dysfunction in patients with type 2 diabetes and with target $\mathrm{HbA1c}$ levels. Diabetes. 2017; 66: 2472-2482.

33 Zoungas S, Patel A, Chalmers J, et al. Severe hypoglycemia and risks of vascular events and death. N Engl J Med. 2010; 363: 1410-1418. $]$

34 Bonds DE, Miller ME, Bergenstal RM, et al. The association between symptomatic, severe hypoglycaemia and mortality in type 2 diabetes: retrospective epidemiological analysis of the ACCORD study. BMJ. 2010; 340 b4909.

35 ADVANCE Collaborative Group, Patel A, MacMahon S, Chalmers $J$ et al. Intensive blood glucose control and vascular outcomes in patients with type 2 diabetes. N Engl J Med. 2008; 358: 2560-2572.

36 Piątkiewicz P, Buraczewska-Leszczyńska B, Kuczerowski R, et al. Severe hypoglycaemia in elderly patients with type 2 diabetes and coexistence of cardiovascular history. Kardiol Pol. 2016; 74: 779-785.

37 Gumprecht J, Nabrdalik K. Hypoglycemia in patients with insulin-treated diabetes. Pol Arch Intern Med. 2016; 126: 870-878.

38 Rana OA, Byrne CD, Greaves K. Intensive glucose control and hypoglycaemia: a new cardiovascular risk factor? Heart. 2014; 100: 21-27.

39 Clark AL, Best CJ, Fisher SJ. Even silent hypoglycemia induces cardiac arrhythmias. Diabetes. 2014; 63: 1457-1459.

40 Gajos G, Konieczynska M, Zalewski J, et al. Low fasting glucose is associated with enhanced thrombin generation and unfavorable fibrin clo properties in type 2 diabetic patients with high cardiovascular risk. Cardiovasc Diabetol. 2015; 14: 44.

41 Chow E, Bernjak A, Williams S, et al. Risk of cardiac arrhythmias during hypoglycemia in patients with type 2 diabetes and cardiovascular risk. Diabetes. 2014; 63: 1738-1747. ‘

42 Middleton TL, Wong J, Molyneaux L, et al. Cardiac effects of sulfonylurea-related hypoglycemia. Diabetes Care. 2017; 40: 663-670. [3

43 Khunti K, Davies M, Majeed A, et al. Hypoglycemia and risk of cardiovascular disease and all-cause mortality in insulin-treated people with type 1 and type 2 diabetes: a cohort study. Diabetes Care. 2015; 38: 316-322.
Goto A, Goto M, Terauchi Y, et al. Association between severe hypoglycemia and cardiovascular disease risk in Japanese patients with type 2 diabetes. J Am Hear Assoc. 2016; 5: e002875

45 Elwen FR, Huskinson A, Clapham L, et al. An observational study of patient characteristics and mortality following hypoglycemia in the community. BMJ Open Diabetes Res Care. 2015; 3: e000094.

46 Lee AK, Warren B, Lee CJ, et al. The association of severe hypoglycemia with incident cardiovascular events and mortality in adults with type 2 diabetes. Diabetes Care. 2018; 41: 104-111. C

47 Fährmann ER, Adkins L, Loader CJ, et al. Severe hypoglycemia and coronary artery calcification during the diabetes control and complication trial/epidemiology of diabetes interventions and complications (DCCT/EDIC study. Diabetes Res Clin Pract. 2015; 107: 280-289.

48 Marso S, McGuire DK, Zinman B, et al. Efficacy and safety of degludec versus glargine in type 2 diabetes. New Engl J Med. 2017; 377: 723-732.

49 Seidu S, Achana FA, Gray LJ, et al. Effects of glucose-lowering and multifactorial interventions on cardiovascular and mortality outcomes: a meta-analysis of randomized control trials. Diabet Med. 2016; 33: 280-289. ए

50 Ross S, Gerstein HC, Eikelboom J, et al. Mendelian randomization analysis supports the causal role of dysglycaemia and diabetes in the risk of coronary artery disease. Eur Heart J. 2015; 36: 1454-1462.

51 Marso SP, Daniels GH, Brown-Frandsen K, et al. Liraglutide and cardiovascular outcomes in type 2 diabetes. N Engl J Med. 2016; 375 311-322. 【

52 Marso SP, Bain SC, Consoli A, et al. Semaglutide and cardiovascular outcomes in patients with type 2 diabetes. New Engl J Med. 2016; 375 1834-1844.

53 Zinman B, Wanner C, Lachin JM, et al. Empagliflozin, cardiovascuar outcomes, and mortality in type 2 diabetes. N Engl J Med. 2015; 373: 2117-2128.

54 Mahaffey K, Neal B, Perkovic V, et al. Canagliflozin for primary and secondary prevention of cardiovascular events: results from the CANVAS Program (Canagliflozin Cardiovascular Assessment Study). Circulation. 2018; 137: 323-334. ¿

55 Drucker DJ. The cardiovascular biology of glucagon-like peptide-1. Cell Metab. 2016; 24: 15-30. ¿

56 Verma S, Goldenberg RM, Bhatt D, et al. Dipeptidyl peptidase-4 inhibitors and the risk of heart failure: a systematic review and meta-analysis. CMAJ Open. 2017; 5: E152-E177.

57 Heerspink H, Perkins B, Fitchett D, et al. Sodium glucose cotransporter 2 inhibitors in the treatment of diabetes mellitus. Circulation. 2016; 134 752-772. ك

58 Neal B, Perkovic V, Mahaffey KW, et al. Canagliflozin and cardiovascular and renal events in type 2 diabetes. N Engl J Med. 2017; 377 644-657. ¿

59 Poreba M, Mostowik M, Siniarski A, et al. Treatment with high-dose $\mathrm{n}-3$ PUFAs has no effect on platelet function, coagulation, metabolic status or inflammation in patients with atherosclerosis and type 2 diabetes. Cardiovasc Diabetol. 2017; 16: 50.

60 Siniarski A, Haberka M, Mostowik M, et al. Treatment with omega-3 polyunsaturated fatty acids does not improve endothelial function in patients with type 2 diabetes and very high cardiovascular risk: A randomized, double-blind, placebo-controlled study (Omega-FMD). Atherosclerosis. 2018; 271: 148-155.

61 Poreba M, Rostoff P, Siniarski A, et al. Relationship between polyunsaturated fatty acid composition in serum phospholipids, systemic low-grade inflammation, and glycemic control in patients with type 2 diabetes and atherosclerotic cardiovascular disease. Cardiovasc Diabetol. 2018; 17: 29. ¿

62 Fitchett D, Mathieu C, Kaspers S, et al. OP 07 Empagliflozin (EMPA) reduces mortality in analyses adjusted for control of blood pressure (BP), low density lipoprotein cholesterol (LDL-C) and $\mathrm{HbA1c}$ over time. Oral presentation \#42 et European Association for the Study of Diabetes Meeting 2017, 12.09.2017.

63 Pratley RE. 1-AC-SY13 new learnings from the results of the liraglutide effect and action in diabetes-Evaluation of Cardiovascular Outcome Results (LEADER) Trial - new results-cardiovascular outcomes. American Diabetes Association 2017, 77th Scientific Sessions, 11.06.2017. 